\title{
Article
}

\section{Applied sport psychology: Are we a profession?}

Winter, S., and Collins, D.

Available at http://clok.uclan.ac.uk/12842/

Winter, S., and Collins, D. ORCID: 0000-0002-7601-0454 (2016) Applied sport psychology: Are we a profession? The Sport Psychologist, 30 (1). pp. 89-96. ISSN 0888-4781

It is advisable to refer to the publisher's version if you intend to cite from the work. http://dx.doi.org/10.1123/tsp.2014-0132

For more information about UCLan's research in this area go to http://www.uclan.ac.uk/researchgroups/ and search for < name of research Group>.

For information about Research generally at UCLan please go to http://www.uclan.ac.uk/research/

All outputs in CLoK are protected by Intellectual Property Rights law, including Copyright law. Copyright, IPR and Moral Rights for the works on this site are retained by the individual authors and/or other copyright owners. Terms and conditions for use of this material are defined in the policies page.

\section{CLoK}

Central Lancashire online Knowledge www.clok.uclan.ac.uk

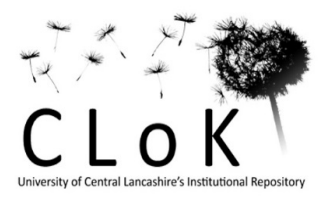


Note: This article will be published in a forthcoming issue of The Sport Psychologist. This article appears here in its accepted, peer-reviewed form, as it was provided by the submitting author. It has not been copy edited, proofed, or formatted by the publisher.

Article Title: Applied Sport Psychology: Are We a Profession?

Authors: Stacy Winter ${ }^{1}$ and David J. Collins ${ }^{2}$

Affiliations: ${ }^{1}$ School of Sport, Health \& Applied Science, St. Mary's University, London, UK. ${ }^{2}$ Institute of Coaching and Performance, University of Central Lancashire, Preston, UK.

Journal: The Sport Psychologist

Acceptance Date: May 13, 2015

(C2015 Human Kinetics, Inc.

DOI: http://dx.doi.org/10.1123/tsp.2014-0132 
“Applied Sport Psychology: Are We a Profession?" by Winter S, Collins DJ

The Sport Psychologist

(C) 2015 Human Kinetics, Inc.

\begin{abstract}
Although the field of applied sport psychology has developed, it faces further challenges on its way towards gaining greater professional status. The following principal criteria of professionalism are proposed as a test of such status (Carr, 1999): (a) provide an important public service; (b) underpinning knowledge base; (c) organizational regulation; (d) distinct ethical dimension; and (e) professional autonomy. This paper undertakes to explore the nature of implications for practice and the extent to which the suggested principal criteria justify a distinctive applied sport psychology profession. In doing so, we hope to stimulate debate on these, and other issues, in order that an even greater professionalization of our applied discipline may emerge.
\end{abstract}

Keywords: sport psychology, professional status, applied practice 
“Applied Sport Psychology: Are We a Profession?" by Winter S, Collins DJ

The Sport Psychologist

(C) 2015 Human Kinetics, Inc.

The umbrella term sport psychology is often defined throughout the literature in relation to the academic discipline. Indeed, Aoyagi and Portenga (2010) highlighted how most of these standard definitions are very broad, vague, and more focused on what sport psychologists research, instead of what they do. Undeniably, while many professionals research and teach sport psychology, they do not necessarily "do" sport psychology (Portenga, Aoyagi, Balague, Cohen, \& Harmison, 2011). Therefore, "while these definitions may be appropriate for the discipline of sport psychology, they are impractical, less relevant, and potentially misleading when applied to the practice and profession of sport psychology" (Portenga et al., 2011, p. 3). For those who focus professionally on "doing," the term applied sport psychology was introduced and is now commonly recognized as having gained professional status (Tod \& Andersen, 2005).

A profession is characterized by an organized body that exists to represent and advance the development of a specialized area (Silva, 1989). While much has been written on the definition of a profession, social theorists describe the dual nature of the professional claim: namely, superiority in knowledge and skill (Freidson 2001). In relation to applied sport psychology, it requires not only a scientific knowledge base and skill set but also a respect for the consumer, a definable ethical standard, and an understanding of the limits of current technique (Gardner, 1991). Accordingly, for applied sport psychology to be a valued profession with an assured future, practitioners need therefore most of all to be seen as relevant, with their work deemed to be useful, as evidenced by their service delivery. This issue is highlighted by Wylleman, Harwood, Elbe, and de Caluwé (2009) "as the field of applied sport psychology is witnessing a growth in interest in professional practice, it is also faced with the challenge of developing its professional status" (p. 435). Thus, the development of professionalism among practitioners of applied sport psychology should be considered as a necessary precondition for further development of the field. 
“Applied Sport Psychology: Are We a Profession?” by Winter S, Collins DJ

The Sport Psychologist

(C) 2015 Human Kinetics, Inc.

However, in achieving (or even claiming to achieve) this professional status, are we aware of what is involved? In short, have we read the small print? To enable an evaluation of this claim, our conceptual analysis focuses upon the following principal criteria of professionalism: (a) professions provide an important public service; (b) they involve a theoretically as well as practically grounded expertise; (c) they require organizational regulation; (d) they have a distinct ethical dimension; and (e) professional practitioners require a high degree of individual autonomy - independent of judgment - for effective practice (Carr, 1999). This paper therefore undertakes to explore, via examination of these commonly suggested criteria of professionalism, the nature of implications for practice and the extent to which they justify a distinctive applied sport psychology profession. In doing so we hope to stimulate both debate and action to move us, if necessary, closer towards a more complete satisfaction of these criteria.

\section{Professions Provide an Important Public Service}

As professionals in a helping profession we need to consider the client's perspective, in which the client is defined as the receiver of treatment/therapy (Collins \& Kamin, 2012). In simple terms, the issues may be conceptualized as the accountability and focus of the work. It has been stated that defining applied sport psychology by what sport psychologists do, will ensure accountability by enhancing congruity between practice and knowledge (Dishman, 1983). However, although this seems to represent a reasonable assertion, it is not a fundamental prerequisite for assuring accountability. Thus, these two distinct areas of interest will be discussed, underpinning this important criterion of professionalism.

The development and public acceptance of any helping profession requires the profession to demonstrate that the procedures used as part of an accepted standard of care do in fact provide the positive results that are claimed. In essence, helping professions should be held accountable for the efficacy of the direct services that they provide (Gardner, 2009). 
“Applied Sport Psychology: Are We a Profession?” by Winter S, Collins DJ

The Sport Psychologist

() 2015 Human Kinetics, Inc.

Sport psychology has throughout its history claimed to embrace psychological skills training as the dominant mode of practice in applied sport psychology (Holt \& Strean, 2001). This practice-oriented branch is often described in terms of athlete performance enhancement, as exemplified by Roper (2002) " the application of psychological techniques and strategies that are aimed at aiding athletes in achieving greater performance', (p. 53). However, given the historical connection and the current era of accountability in the helping professions, it is extremely difficult for applied sport psychology practitioners who purely focus their professional attention on issues of performance enhancement to justify the continued uncritical utilization of traditional interventions (Gardner, 2009). For example, the selfregulatory techniques such as self-talk, imagery, goal-setting, and pre-performance routines commonly associated with the psychological skills training approach.

As noted by Henschen and Tenenbaum (2005) "a prominent issue in sport psychology is the need to develop practice procedures that are accountable and trustful, anecdotal evidence of the effectiveness of applied sport psychology interventions is no longer sufficient to justify the efficacy of the field" (p. 7). Furthermore, limiting sport psychology applications to a purely psychological skills training model might present a dangerously narrow philosophy of service delivery, a factor actually long outlined as a potential disservice to the client (Thompson, 1998). Indeed, several authors have identified the need to elaborate this perspective of applied sport psychology by including, beyond such skill-focused intervention work, a broad array of factors including diagnosis, psychological testing, assessment, counselling, and the provision of clinical services (Aoyagi, Portenga, Poczwardowski, Cohen, \& Statler, 2012; Gardner, 2001).

In relation to this perspective, the field of sport psychology still faces the challenge of formulating an encompassing and uniformly used definition of what applied sport psychology actually entails (Wylleman et al., 2009). To provide clarity for the profession, the practice 
“Applied Sport Psychology: Are We a Profession?” by Winter S, Collins DJ

The Sport Psychologist

(C) 2015 Human Kinetics, Inc.

committee of Division 47 believes applied sport psychology should be conceptualized as a sub-field of performance psychology (Portenga et al., 2011). Recently, Hays (2006) described performance psychology as helping people learn how to perform better and more consistently in endeavors where excellence counts. It is therefore becoming increasingly evident that the core application of sport psychology has been focused on performance excellence; however, there may be some issues with this apparently clear and face-valid perspective.

Traditionally applied sport psychology is, put simply, the application of performance psychology principles designed to help performers reach their potential in the sporting environment. However, it is becoming increasingly common for sport psychologists to find themselves confronted with general well-being issues beyond the scope of performance psychology (such as counselling, clinical, or personality based issues) in the performers with whom they work (Portenga et al., 2011). Exemplified in Gardner and Moore's (2004) taxonomy, which includes concepts such as performance dysfunction and performance impairment, an applied sport psychologist would need to have knowledge of subclinical and clinical issues in order to deal with the full range of classifications. If, for example, assessment suggests performance impairment, and thus by definition a psychological disorder, then general psychological well-being issues would need to be ameliorated first, whether or not they are having an indirect negative influence on athletic performance.

Although it has been highlighted that being able to provide therapeutic services is therefore an important part of a sport psychologist's job responsibilities, it leaves a number of unanswered questions. For example, if applied sport psychology is conceptualized as a subfield of performance psychology how are we integrating performance vs. well-being issues? Are non-performance issues the focus of what applied sport psychology practitioners are being employed to do, and does this expectation extend from individual clients to the teams, 
“Applied Sport Psychology: Are We a Profession?” by Winter S, Collins DJ

The Sport Psychologist

() 2015 Human Kinetics, Inc.

organizations, and institutes who are increasingly the paymaster? Furthermore, and relating to the codes of practice criterion (item d), are practitioners equipped with the skills, necessary training and, most importantly from an ethical viewpoint, competent and appropriately qualified to deal with such issues? Together these questions all highlight potential issues for the different organizations responsible for training individuals in the field of applied sport psychology.

Herzog and Hays (2012) recently argued practitioners needed to be knowledgeable and versatile as there is no one right solution but rather, many potential pathways (cf. Martindale \& Collins, 2005). As illustrated, applied sport psychology has therefore not confronted the fact that it has consisted of (at least) two very different foci: performance excellence and therapy (Aoyagi et al., 2012). However, regardless of the service being delivered, this provision primarily centers on one-to-one support work with clients. An additional practice focus arises when the applied practitioner is involved in providing psychological services to a sporting team or organization. Sporting environments, in particular high performance ones, are laden with challenging realities that require different roles as practitioners intervene within multiple organizational levels (Portenga et al., 2011). As Fletcher and Wagstaff (2009) highlighted, it is, therefore, essential for sport psychology practitioners to better understand organizational influences on athletic performance. The future for applied sport psychology may therefore require some careful extension to existing generic and more therapy-oriented codes of conduct, notwithstanding the focus-related issues of performance versus individual (Collins \& Kamin, 2012; Gardner, 1991). Consequently, this could therefore be the most difficult, yet crucial criterion for professional bodies to focus on in the advancement of applied sport psychology as a profession. 
“Applied Sport Psychology: Are We a Profession?" by Winter S, Collins DJ

The Sport Psychologist

(C) 2015 Human Kinetics, Inc.

\section{Professional Knowledge Base}

Consider criterion (b), which suggests that professional competence cannot be merely practically acquired but also requires significant (perhaps a priori?) theoretical knowledge. It is widely assumed that, in any applied discipline, scientist-practitioners seek guidance from a prevailing theoretical and empirical paradigm to underpin, inform, and guide their practice. As supported by Gardner (2009), the development and acceptance of any scientific discipline requires an ever expanding and maturing empirical base. Where professional practice is concerned, adherence to the working model of theory-research-practice (Smith \& Smoll, 2011) should help ensure that the actions of practitioners are grounded upon firm theoretical and research findings. The development of this evidence-based practice is fairly recent and primarily evolved out of concerns about the serious divide between available professional knowledge and the services offered by professionals (Moore, 2007). It is, therefore, seen as fundamental to engage in evidence-based practice at the forefront of issues regarding the provision of applied sport psychology and is consistent with the demands of being a profession (cf. Cropley, Hanton, Miles, \& Niven, 2010; Winter \& Collins, 2015a).

A comparative weakness in practice-based knowledge has been widely documented however, specifically that the application of theory to practice is problematic within applied sport psychology (Martens, 1979; Winter \& Collins, 2015b; Winter, MacPherson, \& Collins, 2014). In addressing such issues, we would firstly suggest that some careful and critical consideration is paid to what might be described as the epistemological origin of the knowledge underpinning our profession. Sport psychologists who wish to practice or apply their specialization should be differentiated from that of research specialists (Silva, 1989); indeed, this has been the case in some previous accreditation systems (for example, the British Association of Sport and Exercise Sciences - BASES). The contention is that different aims within any scientific discipline generate distinctly different types of 
“Applied Sport Psychology: Are We a Profession?” by Winter S, Collins DJ

The Sport Psychologist

(C) 2015 Human Kinetics, Inc.

knowledge. In our field of sport psychology this relates to: psychology through, of, and for performance (Collins, 2008; Collins \& Kamin, 2012). Accordingly, research-practitioner knowledge is more likely to be influenced by domain-specific knowledge, psychology for performance, than by the other components.

For example, research-practitioners and support providers utilize psychological principles and methodologies to benefit the performance of specific individuals, teams, or groups; intra- individual or team/group specific work focused on understanding and enhancing performance for this particular group, rather than theory development. The more descriptive ideographic material from psychology for performance knowledge is most likely to drive forward support-practitioner behavior, compared to psychology through (generating knowledge for psychology through examination of performance), or of (generating a knowledge of sport psychology, which may be of relevance to performance) performance resulting in the generation of literature that is publication-focused rather than on the applied implications per se. As Cascio (2008) stated "to date, much of the effort by academics to reach out to practitioners has focused on the diffusion of scientific knowledge, not its creation. For genuine change to occur, it is necessary to promote much closer collaboration between academics and practitioners" (p. 455).

Any idea of a straightforward link between theory and professional practice is consequently problematic. Although theories certainly aim at truth they are also frequently provisional or speculative and function more to guide, than strictly determine practice (Carr, 1999). Accordingly, because competing theories may well lay claim to our allegiance in a given professionally problematic situation - the very idea of professional theory seems prone to an insufficiently noted ambiguity (Carr, 1999). Realistically, the advancement of true professionalism therefore requires that as practitioners we admit to gaps in knowledge and accept the fact that our work is continually undergoing a learning process (Gardner, 1991). 
“Applied Sport Psychology: Are We a Profession?” by Winter S, Collins DJ

The Sport Psychologist

() 2015 Human Kinetics, Inc.

Being able to attend to the three reciprocal linkages of theory-research-practice will enable sport psychology practitioners to ensure that the knowledge, research, and interventions will support one another and advance the field as a profession, especially, if focused on domainspecific knowledge, psychology for performance.

\section{Organizational Regulation}

At present, the discipline and practice of sport psychology in North America is represented by two primary professional organizations: the Association for Applied Sport Psychology (AASP) and Division 47 of the American Psychological Association (APA). Both of these organizational programmes acknowledge the importance of performance in their definitions of sport psychology and, in preparing for applied sport psychology, generally emanate from educational institutes (Burke, Sachs, Fry, \& Schweighardt, 2008). Similarly, in the UK, the BASES and the British Psychological Society (BPS) both offer supervised experience programmes that result in, respectively, accreditation leading to chartered scientist or chartered status in psychology. These professional training frameworks are mechanisms for ensuring quality and professionalism by recognizing the practitioners' ability to demonstrate professional competence and practice independently (Cropley et al., 2010). On the surface, these regulatory bodies therefore seem to serve a critical need for the profession of sport psychology: identifying the minimum qualifications, education, and experiences necessary to deliver applied sport psychology services.

However, although each was developed to serve the public good and provide some insight into the competencies needed to effectively and ethically practice sport psychology, pragmatically they leave significant gaps (Aoyagi et al., 2012). Perhaps most problematically, no organization has taken a position on distinguishing performance-based work from therapeutically based work with athletes (cf. Herzog \& Hays, 2012). As an interdisciplinary field, there is an assumption that all applied sport psychology practitioners 
“Applied Sport Psychology: Are We a Profession?” by Winter S, Collins DJ

The Sport Psychologist

(C) 2015 Human Kinetics, Inc.

should have training in both clinical/counselling as well as psychological skills training, but there are clearly various levels of expertise based on what each individual specializes in (Roberts, 2006). Although this current debate exists within AASP and APA trained individuals, interestingly in the UK no clinical training is offered within either the BPS or BASES pathways. As Weinberg (2014) recently stated, "many professional organizations want individuals who can handle both the mental skills and clinical aspects of sport psychology consultancy. Thus, new professionals need to get enhanced training/education, to meet the needs of current clients and organizations and increase their potential for securing employment" (p. 36).

Offering a potential milestone for the profession, the Australian model of sport psychology sits apart from the dominant training pathways. Future practitioners are educated as general psychologists first, and as sport psychologists second, adapting a training model from the Australian Psychological Society board of clinical psychologists (Morris, 1995). Bona fide service delivery requires practitioners to forge strong therapeutic relationships, conceptualize cases using sound theoretical frameworks, and work collaboratively with clients on agreed upon goals - much the same as traditional psychological service delivery (Hanrahan \& Andersen, 2010). As previously discussed, some authors have suggested that acknowledging broader psychological (and even clinical) issues in the sporting environment is outside of the realms of performance psychology. On the contrary, this model views helping athletes acknowledge and address their psychological issues (e.g., depression, relationship concerns, eating disorders) as having an indirect positive influence on their sporting performances (Sebbens, Andersen, \& Hanrahan, 2012).

Both clinical and performance enhancement components are indeed important in applied sport psychology work, but arguably the emphasis depends on personal preference, training, expertise and, of course, staying within one's realm of competence. This issue of 
“Applied Sport Psychology: Are We a Profession?” by Winter S, Collins DJ

The Sport Psychologist

(C) 2015 Human Kinetics, Inc.

competence is not new to practicing psychologists who strive to operate within their professional boundaries (Fletcher \& Maher, 2013). Competence has been recognized as a central principle and value that underpins service delivery (Barnett, Doll, Younggren, $\&$ Rubin, 2007). However, the field of sport psychology draws from several disciplines and is made up of practitioners from very different avenues of study, for example, psychology, sport science, and pure kinesiology. Therefore, although competence is perceived to be of vital importance for all consulting psychologists, maybe not surprisingly no regulatory body has provided a specific and clear definition of competence that may be used within the field of applied sport psychology (Brown \& Cogan, 2006; Tod, Marchant, \& Andersen, 2007; Wylleman et al. 2009). Thus, practitioners and, more importantly, clients can remain confused over what defines and delimits the practice of sport psychology (Aoyagi et al., 2012).

It could, therefore, be suggested that organizations take note of the Australian model in offering an innovative breakthrough to create and enforce an adequate regulation of the applied sport psychology profession. However, although the pathway in Australia is seen by some as perhaps the most integrated training and registration model of sport psychologists in the world (Andersen, 2001), those adopting the prominent performance psychology philosophy to applied practice would argue against this framework (cf. Portenga et al., 2011). For example, the Australian approach may pursue clinical knowledge and skills at the expense of more performance-focused elements such as skill acquisition/refinement and a broader performance science focus, such as nutritional impacts of mental aspects. As highlighted previously in criterion (a) of this paper, until an encompassing and uniformly used definition of what applied sport psychology entails is formulated, this field will remain incredibly and uniquely hard to regulate. 
“Applied Sport Psychology: Are We a Profession?" by Winter S, Collins DJ

The Sport Psychologist

(C) 2015 Human Kinetics, Inc.

\section{Ethical Code of Practice}

"Whereas a good tradesman or salesperson is first and foremost someone who is procedurally skilled, a good professional also possesses, in addition to specified theoretical or technical expertise, a range of distinctly moral and ethical attitudes designed to elevate the interests and needs of clients, above self-interest" (Carr, 1999, p. 36). The core of applied sport psychology should therefore include a consideration of the fundamental ethics in professional practice. Hence, it is often regarded as crucial to what shall be counted as acceptable conduct and to ensuring control over standards, that any profession worthy of the name ought to be governed by a code of professional ethics, which clearly identifies professional obligations and responsibilities by reference to the rights of clients (Brown \& Cogan, 2006; Carr, 1999; Stapleton, Hankes, Hays, \& Parham, 2010). Of course, this issue of professional ethics is complex and multifaceted. Against this agenda, all pertinent bodies (e.g., AASP, APA, BASES, BPS) must play a preferably integrated role in setting and publicizing standards (Collins \& Kamin, 2012); indeed, apart from servicing the interests of their memberships, this is arguably their primary role as professional bodies.

Although these programmes have undergone review over recent years in attempts to meet the demands associated with the professionalization of the field, it has still been recently stated "one of the main overarching messages to emerge is that current training and development documentation are inadequate in terms of preparing trainees in all the necessary competencies for applied sport psychology" (Fletcher \& Maher, 2013, p. 275). The ethical principles of psychologists and code of conduct of the APA (2002) clearly indicates the expectation that sport psychologists will only practice within their scope of competence, based on their education, training, supervised experience, consultation, or professional experience (Stapleton et al., 2010). Practitioners working within applied sport psychology are therefore required to practice within the boundaries of their competence, governed by 
“Applied Sport Psychology: Are We a Profession?” by Winter S, Collins DJ

The Sport Psychologist

(C) 2015 Human Kinetics, Inc.

their regulatory body. Moreover, these professional organizations have established policies, guidelines, and standards to regulate the development, certification, and maintenance of competence. However, due to the novelty of this field of study, the ethical issues faced by sport psychology practitioners often differ to some degree from those who practice a more traditional form of psychology (Brown \& Cogan, 2006).

Specifically for the sport psychologist, ethical challenges not only include those typically faced by traditional clinical and counseling psychologists but also those dilemmas that arise as a result of the particular service demands that accompany practice with such a unique clientele (Watson, Zizzi, \& Etzel, 2006). For sport psychologists practicing in nontraditional settings, many of the ethical guidelines do not in fact represent the particular demands of the setting, or the exceptional necessities that accompany their professional work and delivery of services (Moore, 2003). For example, meeting athletes at the training ground, during team travel, or over dinner because of time constraints, may be necessary in order to provide needed services, but could be viewed as breaching boundary issues or as a violation of client confidentiality. However, such spontaneous and compromising decisions echo the demands of the sport psychologist and must be carefully considered (Petitpas, Brewer, Rivera, \& Van Raalte, 1994). Such dichotomous professional difficulties are central to the practice of applied sport psychology, yet even with the presence of ethical standards to guide practice, these difficult questions are often left without clear and practical answers (Moore, 2003).

Ethical considerations in applied sport psychology can be numerous and diverse, especially given the specialty of services given to athletics in often nontraditional settings; indeed, to be effective a sport psychologist must respond in a distinctive fashion within a unique cultural experience (Etzel \& Watson, 2006). Therefore as discussed earlier in the professions provide an important public service section (a), when a sport psychologist works 
“Applied Sport Psychology: Are We a Profession?” by Winter S, Collins DJ

The Sport Psychologist

(C) 2015 Human Kinetics, Inc.

with an athlete, especially at the elite level of their sport, can personal or clinical issues be separated from the athlete's performance issues? If at the elite level of sport everything is performance focused, then the sport psychologist must be prepared to work with the entire athlete and that requires competence in all aspects that applied sport psychology entails. In short, authors have agreed that when concerned about the ethicality when working in the athletic arena, the profession should be aware of the differences between sport psychology and traditional psychology, and always be willing to consult with a fellow practitioner (Brown \& Cogan, 2006; Stapleton et al., 2010).

\section{Professional Autonomy}

Adequate professionalism in sport psychology requires that issues such as training requirements and certification be carefully considered. However, beyond these broad organizational issues the individual practitioner must, if expected to practice at a high level of professionalism, develop the broad knowledge necessary to make sound professional judgments (Gardner, 1991). Thus, there would appear to be a link between the theoryimplicatedness of professional practice and the need for professional autonomy specified in criterion (e). Since professionals are often confronted with unprecedented cases, independent judgment is needed to match theoretical generalities to particular contingencies (Carr, 1999). At its most basic level, evidence-based practice describes a means of facilitating wellreasoned decisions by encouraging the practitioner to effectively integrate scientific research findings, the preferences, circumstances, and uniqueness of each client, and his or her professional judgment (Moore, 2007; Winter \& Collins, 2015a).

In response, and as an active effort to reduce the serious divide between research and practice as highlighted in criterion (b), evidence-based practice involves the ongoing and explicit use of current best evidence in making decisions about the care of individual clients (Sackett, Rosenberg, Gray, Haynes, \& Richardson, 1996). The recognition that evidence- 
“Applied Sport Psychology: Are We a Profession?” by Winter S, Collins DJ

The Sport Psychologist

() 2015 Human Kinetics, Inc.

based practice is important for allowing sport psychologists to make informed decisions

(Gardner \& Moore, 2006) advocates the practitioner's ability to enhance the accuracy and validity of his or her applied practice, through professional judgment and decision-making (Martindale \& Collins, 2005). More specifically, professional judgment and decision-making is the tool through which practitioners can best develop and deploy a bespoke solution to optimally address the client's presenting condition and stated needs.

Professional theory is, by the same token, more often advisory than precisely prescriptive. Responsible professional decisions must ultimately depend on the quality of personal deliberation and reflection by each individual sport psychologist (Carr, 1999). Supported by a growing literature, professional practice (and medical practice in particular e.g., Husted \& Husted, 1995) is characterized by complexity, uncertainty, and unpredictability. Practitioners use their judgment and wisdom developed in their own practice and in their contacts with fellow practitioners. Often, practitioners choose between options that are not ideal, and may need to decide on what they believe is best for an individual rather than what is right in some absolute sense (Coles, 2006; Winter \& Collins, 2015b).

Perhaps reflecting this complexity, some authors have noted that the conceptualization stage can be glossed over, with the practitioner moving directly from needs assessment to intervention, drawing more on well-known and preferred strategies than a bespoke plan for the exact parameters of that particular client's situation (Martindale \& Collins, 2005; Poczwardowski, Sherman, \& Henschen, 1998). Often referred to in counselling psychology as the configuration of the client's problem (Cormier \& Cormier, 1991), this stage should represent an optimum meld of client need, practitioner philosophy, and the various components of the presenting condition. In turn, this provides a strong drive toward careful and critical consideration of process decisions. Professional autonomy 
“Applied Sport Psychology: Are We a Profession?” by Winter S, Collins DJ

The Sport Psychologist

(C) 2015 Human Kinetics, Inc.

therefore also advances and structures the profession's current preoccupation with critical reflection (cf. accreditation guidelines for BASES and AASP). In short, careful consideration of the whys, and why nots of an action is crucial for the emerging but diverse profession of applied sport psychology (cf. Martindale \& Collins, 2010).

\section{Conclusion}

The primary purpose of this article has been to encourage thought and reflection among individuals involved in the multidisciplinary profession of sport psychology. Although the field of applied sport psychology has developed, it faces major challenges on its way towards gaining greater professional status (Anderson \& Lavallee, 2005). Thus, the critical topics to consider include determining what actually constitutes sport psychological practice, practicing within one's areas of competence, understanding what training is required to provide what service, developing the practice-based knowledge necessary to make sound professional judgments, and acknowledging the ethical flexibility needed for the profession. Of course, these issues have already been well aired in sport psychology journals. The lack of clear actions and conclusions, however, in addition to the continued presence of some problems and the proliferation of others, suggests that the topic is still worthy of debate.

Specifically, and despite the broad debate to date, the development of the practice of sport psychology has been hindered and, we suggest, is still limited, by the lack of a clear understanding of what the field encapsulates. A clearer definition of applied sport psychology will ensure consumers receive competent, effective services and avoid coaches and athletes giving up on sport psychology because they can see that the profession lacks a consistent identity (Portenga et al., 2011). Despite the fact that there has been discussion around a range of professional practice issues in the sport psychology literature, there do not seem to be practical models or frameworks that can guide the practitioner conceptually, procedurally, and technically in their work. In considering the future of this discipline, it is 
“Applied Sport Psychology: Are We a Profession?” by Winter S, Collins DJ

The Sport Psychologist

(C) 2015 Human Kinetics, Inc.

therefore apparent that the first issue to be resolved is defining the practice and profession of applied sport psychology (Aoyagi et al., 2012).

Additionally, with the surge of professional interest in this field, it is particularly important to optimize the vocational development of applied sport psychology by way of ensuring the quality of service delivery and the competency development of practitioners (Wylleman et al., 2009). At the core of each professional concern, lies the need for training to be commensurate with the demands of the applied sport psychology services being delivered. The sport context is a unique performance environment that could arguably require understanding in performance psychology, mental skills, motor learning and control, organizational psychology, assessment, counselling, and clinical psychology. The profession is undoubtedly broad and hence, debatably, it is unresolved whether training should be encompassing of all these areas. Or, alternatively, there actually needs to be room for sport psychologists having different foci and specializations within the field, for example: clinical, organizational, and/or performance psychology. Adoption of such a medical model, with clearly delineated and valued foci, would surely also need a common, medico-like, knowledge and experience base before specialization.

Furthermore, we feel there is a need to strengthen the field while maintaining professional freedom and ethical responsibility. In the formulation of codes of professional and ethical conduct it is important due to the novelty of this field of study, that the profession should be aware of the differences between sport psychology from those who practice a more traditional form of psychology (Brown \& Cogan, 2006; Stapleton et al., 2010). Our ethical guidelines therefore more accurately need to represent sport psychologists practicing in nontraditional settings and the particular demands of these settings that accompany the delivery of services (Moore, 2003). Finally, it may be applied sport psychology has been too lenient on research that clearly falls outside of the realm of acceptable scientific knowledge 
“Applied Sport Psychology: Are We a Profession?” by Winter S, Collins DJ

The Sport Psychologist

(C) 2015 Human Kinetics, Inc.

for the profession (Winter et al., 2014). Developing the practice-based knowledge necessary to make sound professional judgments (Martindale \& Collins, 2005) is therefore fundamental if we truly seek to become an evidence-based practice. We see this as the most direct route to a long-term integration of science and practice, to an improvement of accountability, and as a major factor in the sustainability of applied sport psychology as a profession.

This paper has argued that the future of applied sport psychology as a successful and long-term profession is not automatically assured; rather, that there are many challenges to be faced. It is therefore suggested that sport psychologists and regulatory bodies have to understand the nature of these challenges and embrace change where necessary. At all times the profession must be seen to be relevant and capable of providing valuable services to its unique clientele. With a strong foundation, a positive future is indeed within the profession's grasp; nevertheless, it is the manner in which applied sport psychology meets the challenges ahead that will determine whether such a positive outcome is in fact achieved. It is thus the hope of the authors, that this paper will stimulate debate on these, and other issues, in order that an even greater professionalization of our applied discipline may emerge. 
“Applied Sport Psychology: Are We a Profession?” by Winter S, Collins DJ

The Sport Psychologist

(C) 2015 Human Kinetics, Inc.

\section{References}

Andersen, M. B. (2001). Training and supervision in sport psychology. In G.T. Wilson (Clinical and Applied Psychology Section Ed.), International Encyclopedia of the Social and Behavioral Sciences (pp. 14929-14932). Oxford, England: Elsevier Science.

Anderson, A., \& Lavallee, D. (2005). Professional development issues in Britain: Lessons from Australia and the USA. Sport \& Exercise Psychology Review, 1, 12-16.

Aoyagi, M. W., \& Portenga, S. T. (2010). The role of positive ethics and virtues in the context of sport and performance psychology service delivery. Professional Psychology: Research and Practice, 41, 253-259. doi:10.1037/a0019483

Aoyagi, M. W., Portenga, S. T., Poczwardowski, A., Cohen, A. B., \& Statler, T. (2012). Reflections and directions: The profession of sport psychology past, present, and future. Professional Psychology: Research and Practice, 43, 32-38. doi:10.1037/a0025676

Barnett, J. E., Doll, B., Younggren, N., \& Rubin, N. J. (2007). Clinical competence for practicing psychologists: Clearly a work in progress. Professional Psychology: Research and Practice, 38, 510-517. doi:10.1037/0735-7028.38.5.510

Brown, J. L., \& Cogan, K. D. (2006). Ethical clinical practice and sport psychology: When two worlds collide. Ethics \& Behavior, 16, 15-23. doi:10.1207/s15327019eb1601_3

Burke, K. L., Sachs, M. L., Fry, S. J., \& Schweighardt, S. L. (2008). Directory of graduate programs in applied sport psychology (9th ed.). Morgantown, WV: Fitness Information Technology.

Carr, D. (1999). Professional education and professional ethics: Right to die or duty to live? Journal of Applied Philosophy, 16, 33-46. doi:10.1111/1468-5930.00106

Cascio, W. F. (2008). To prosper, organizational psychology should. . .bridge application and scholarship. Journal of Organizational Behavior, 29, 455-468. doi:10.1002/job.528

Coles, C. (2006). Uncertainty in a world of professional regulation. Advances in Psychiatric Treatment, 12, 397-403. doi:10.1192/apt.12.6.397

Collins, D. (2008, December). Strange Bedfellows: Why sport AND exercise psychology? Invited keynote at the inaugural British Psychological Society DSEP Conference, London.

Collins, D., \& Kamin, S. (2012). The performance coach. In S. H. Murphy (Ed.). The oxford handbook of sport and performance psychology (pp. 692-706). New York, NY: Oxford University Press.

Cormier, W. H., \& Cormier, S. L. (1991). Interviewing strategies for helpers. Fundamental skills and cognitive behavioral interventions ( $3^{\text {rd }} \mathrm{ed}$.). Pacific Grove, CA: Brooks/Cole. 
“Applied Sport Psychology: Are We a Profession?” by Winter S, Collins DJ

The Sport Psychologist

(C) 2015 Human Kinetics, Inc.

Cropley, B., Hanton, S., Miles, A., \& Niven, A. (2010). Exploring the relationship between effective and reflective practice in applied sport psychology. The Sport Psychologist, $24,521-541$.

Etzel, E. F., \& Watson, J. C. (2006). Ethics in sport and exercise psychology. Ethics and Behavior, 16, 1-3.

Dishman, R. K. (1983). Identity crises in north American sport psychology: Academics in professional issues. Journal of Sport Psychology, 5, 123-134.

Fletcher, D., \& Maher, J. (2013). Toward a competency-based understanding of the training and development of applied sport psychologists. Sport, Exercise, and Performance Psychology, 2, 265-280. doi: 10.1037/a0031976

Fletcher, D. \& Wagstaff, C. R. D. (2009). Organizational psychology in elite sport: Its emergence, application and future. Psychology of Sport and Exercise, 10, 427-434. doi:10.1016/j.psychsport.2009.03.009

Freidson, E. (2001). Professionalism: The third logic. Cambridge, UK: Polity Press.

Gardner, F. L. (1991). Professionalization of sport psychology: A reply to Silva. The Sport Psychologist, 5, 55-60.

Gardner, F. L. (2001). Applied sport psychology in professional sports: The team psychologist. Professional Psychology: Research and Practice, 32, 34-39. doi:10.1037/0735-7028.32.1.34

Gardner, F. L. (2009). Efficacy, mechanisms of change and the scientific development of sport psychology. Journal of Clinical Sport Psychology, 3, 139-155.

Gardner, F. L., \& Moore, Z. E. (2004). The Multi-level classification system for sport psychology (MCS-SP). The Sport Psychologist, 18, 89-109.

Gardner, F. L., \& Moore, Z. E. (2006). Clinical sport psychology. Champaign, IL: Human Kinetics.

Hanrahan, S. J., \& Andersen, M. B. (2010). Routledge handbook of applied sport psychology: A comprehensive guide for students and practitioners. London: Routledge.

Hays, K. F. (2006). Being fit: The ethics of practice diversification in performance psychology. Professional Psychology: Research and Practice, 37, 223-232. doi:10.1037/0735-7028.37.3.223

Henschen, K., \& Tenenbaum, G. (2005). Introduction. In G. D. Hackfort, J. L. Duda, \& R. Lidor (Eds.), Handbook of research in applied sport and exercise psychology: International perspectives. Morgantown, WV: Fitness Information Technology.

Herzog, T. \& Hays, K. F. (2012). Therapist or mental skills coach? How to decide. The Sport Psychologist, 26, 486-499.

Holt, N. L., \& Strean, W. B. (2001). Reflecting on initiating sport psychology consultation: A self-narrative of neophyte practice. The Sport Psychologist, 15, 188-204. 
“Applied Sport Psychology: Are We a Profession?” by Winter S, Collins DJ

The Sport Psychologist

(C) 2015 Human Kinetics, Inc.

Husted, G. L., \& Husted, J. H. (1995). Ethical decision making in nursing. New York: Mosby Inc.

Martens, R. (1979). About smocks and jocks. Journal of Sport Psychology, 1, 94-99.

Martindale, A., \& Collins, D. (2005). Professional judgment and decision making: The role of intention for impact. The Sport Psychologist, 19, 303-317.

Martindale, A., \& Collins, D. (2010). But why does what works work? A response to Fifer, Henschen, Gould, and Ravizza. The Sport Psychologist, 24, 113-116.

Moore, Z. E. (2003). Ethical dilemmas in sport psychology: Discussion and recommendations for practice. Professional Psychology: Research and Practice, 34, 601-610. doi:10.1037/0735-7028.34.6.601

Moore, Z. E. (2007). Critical thinking and the evidence-based practice of sport psychology. Journal of Clinical Sport Psychology, 1, 9-22.

Morris, T. (1995). Sport psychology in Australia: A profession established. Australian Psychologist, 30, 128-134.

Petitpas, A. J., Brewer, B. W., Rivera, P. M., \& Van Raalte, J. L. (1994). Ethical beliefs and behaviors in applied sport psychology: The AAASP ethics survey. Journal of Applied Sport Psychology, 6, 135-151. doi:10.1080/10413209408406290

Poczwardowski, A., Sherman, C. P., \& Henschen, K. P. (1998). A sport psychology delivery heuristic: Building theory on practice. The Sport Psychologist, 12, 191-207.

Portenga, S. T., Aoyagi, M. W., Balague, G., Cohen, A., \& Harmison, B. (2011). Defining the practice of sport and performance psychology. American Psychological Association. Retrieved from: http://www.apadivisions.org/division47/about/resources/defining.pdf

Roberts, M. C. (2006). Essential tension: Specialization with broad and general training in psychology. American Psychologist, 61, 862-870. doi:10.1037/0003-066X.61.8.862

Roper, E. A. (2002). Women working in the applied domain: examining the gender bias in applied sport psychology. Journal of Applied Sport Psychology, 14, 53-66. doi:10.1080/10413200209339011

Sackett, D. L., Rosenberg, W. M. C., Gray, J. A. M., Haynes, R. B., \& Richardson, W. S. (1996). Evidence-based medicine: What it is and what it isn't. British Medical Journal, 312, 71-72.

Sebbens, J., Andersen, M., \& Hanrahan, S. (2012). Beyond performance: Training sport psychologists in Australia. Australian Psychological Society. Retrieved from: http://www.psychology.org.au/Content.aspx?ID=4990

Silva, J. M. (1989). Toward the professionalization of sport psychology. The Sport Psychologist, 3, 265-273. 
“Applied Sport Psychology: Are We a Profession?" by Winter S, Collins DJ

The Sport Psychologist

(C) 2015 Human Kinetics, Inc.

Smith, R. E., \& Smoll, F. L. (2011). Cognitive-behavioral coach training: A translational approach to theory, research, and intervention. In J. K. Luiselli \& D. D. Reed (Eds.), Behavioral sport psychology: Evidence-based approaches to performance enhancement (pp. 227-248). London: Springer.

Stapleton, A. B., Hankes, D. M., Hays, K. F., \& Parham, W. D. (2010). Ethical dilemmas in sport psychology: A dialogue on the unique aspects impacting practice. Professional Psychology: Research and Practice, 41, 143-152. doi:10.1037/a0017976

Thompson, M. A. (1998). A philosophy of applied sport psychology. In M. A. Thompson, R. A. Vernacchia, \& W. E. Moore (Eds.), Case studies in sport psychology: An educational approach (pp. 3-7). Dubuque, IA: Kendall/Hunt.

Tod, D., \& Andersen, M. B. (2005). Success in sport psych: Effective sport psychologists. In S. Murphy (Ed.), The sport psych handbook (pp. 305-315). Champaign, IL: Human Kinetics.

Tod, D., Marchant, D., \& Andersen, M. B. (2007). Learning experiences contributing to service delivery competence. The Sport Psychologist, 21, 317-334.

Watson, J. C., Zizzi, S., \& Etzel, E. F. (2006). Ethical training in sport psychology programs: Current training standards. Ethics and Behavior, 16, 5-14.

Weinberg, R. (2014). On becoming a sport psychology consultant: What a long strange trip it's been. In P. J. McCarthy \& M. V. Jones (Eds.), Becoming a sport psychologist (pp.28-37). Hove, UK: Routledge.

Winter, S., \& Collins, D. (2015a). Where is the evidence in our sport psychology practice? A United Kingdom perspective on the underpinnings of action. Professional Psychology: Research \& Practice. doi:10.1037/pro0000014

Winter, S., \& Collins, D. (2015b). Why do we do, what we do? Journal of Applied Sport Psychology, 27, 35-51. doi:10.1080/10413200.2014.941511.

Winter, S., MacPherson, A. C., \& Collins, D. (2014). "To think, or not to think, that is the question" Sport, Exercise, and Performance Psychology, 3, 102-115. doi:10.1037/spy0000007

Wylleman, P., Harwood, C. G., Elbe, A. M., \& de Caluwé, D. (2009). A perspective on education and professional development in applied sport psychology. Psychology of Sport and Exercise, 10, 435-446. doi:10.1016/j.psychsport.2009.03.008 